\title{
Intracranial stimulation of the trigeminal nerve in man. III. Sensory potentials
}

\author{
G CRUCCU,* M INGHILLERI, $†$ M MANFREDI, $\uparrow$ M MEGLIO $\ddagger$
}

From the Pain Relief Foundation and *Department of Neurosciences, Walton Hospital, Liverpool, UK, $\dagger$ Department of Neurosciences, University of Rome "La Sapienza" and $\ddagger$ Institute of Neurosurgery, Universita' Cattolica, Rome, Italy

SUMMARY Percutaneous electrical stimulation of the trigeminal root was performed in 18 subjects undergoing surgery for idiopathic trigeminal neuralgia or implantation of electrodes into Meckel's cave for recording of limbic epileptic activity. All subjects had normal trigeminal reflexes and evoked potentials. Sensory action potentials were recorded antidromically from the supraorbital (V1), infraorbital (V2) and mental (V3) nerves. In the awake subject, sensory potentials were usually followed by myogenic artifacts due to direct activation of masticatory muscles or reflex activation of facial muscles. In the anaesthetised and curarised subject, sensory potentials from the three nerves showed 1.4-2.2 ms onset latency, 1.9-2.7 ms peak latency and 17-29 $\mu \mathrm{V}$ amplitude. Sensory conduction velocity was computed at the onset latency (maximum $\mathrm{CV}$ ) and at the peak latency (peak CV). On average, maximum and peak CV were 52 and $39 \mathrm{~m} / \mathrm{s}$ for V1, 54 and $42 \mathrm{~m} / \mathrm{s}$ for V2 and 54 and $44 \mathrm{~m} / \mathrm{s}$ for V3. There was no apparent difference in CV between subjects with trigeminal neuralgia and those with epilepsy. A significant inverse correlation was found between CV and age, the overall maximum CV declining from $59 \mathrm{~m} / \mathrm{s}$ (16 years) to $49 \mathrm{~m} / \mathrm{s}$ (73 years). This range of CV is compatible both with histometric data and previous electrophysiological findings on trigeminal nerve conduction. Intraoperative intracranial stimulation is also proposed as a method of monitoring trigeminal function under general anaesthesia.

The cutaneous branches of the trigeminal nerve remain in the depth of craniofacial structures for most of their course, and emerge on the surface of the face in the proximity of their target skin territory, dividing into thin, short, terminal fascicles. This leaves little room for stimulation and recording of nerve fibres in intact man, hence the absence of normative data on trigeminal nerve conduction.

The available electroneurographic data have been achieved by intraoperative recordings, either by recording from ${ }^{12}$ or by stimulation of ${ }^{34}$ the ganglion and root, in subjects undergoing surgery for trigeminal neuralgia.

This paper describes the sensory action potentials (SAPs) evoked in the supraorbital, infraorbital and mental nerves, by direct electrical stimulation of the trigeminal root, and the sensory conduction velocity

Address for reprint requests: $\mathrm{Dr} G$ Cruccu, Dipartimento Scienze Neurologiche, Viale Universita', 3000185 Roma, Italy.

Received 31 October 1986. Accepted 27 January 1987.
(CV) of the three branches, in patients suffering from idiopathic trigeminal neuralgia or temporal lobe epilepsy.

\section{Material and methods}

The study was carried out in 18 subjects of either sex aged 16-73 years (mean age, 51). Four subjects, suffering from complex partial seizures suspected to be of mesio-basal limbic origin, were being submitted to implantation of permanent electrodes into Meckel's cave for recording of limbic electrical activity. ${ }^{5}$ Fourteen subjects, diagnosed as having idiopathic trigeminal neuralgia, were undergoing percutaneous interventions on the ganglion and root by radiofrequency thermocoagulation ${ }^{6}$ or balloon microcompression $^{7}$ or chronic electrical stimulation. ${ }^{8}$

In all subjects trigeminal function was examined a few days before surgery by means of electrophysiological testing of trigeminal reflexes: corneal reflex evoked by electrical stimulation of the cornea, blink reflex evoked by electrical stimulation of the supraorbital and infraorbital nerves, masseter silent periods evoked by electrical stimulation of the infraorbital and mental nerves, jaw-jerk to taps to the chin. ${ }^{9}$ In the immediate preoperative period, nine subjects were 
Table 1 Comparison of SAPs from the three trigeminal divisions in 6 selected cases* (Mean $\pm S D$ )

\begin{tabular}{lccccc}
\hline Nerve & $\begin{array}{l}\text { Distance } \\
(\mathrm{mm})\end{array}$ & $\begin{array}{l}\text { Onset latency } \\
(\mathrm{ms})\end{array}$ & $\begin{array}{l}\text { Peak latency } \\
(\mathrm{ms})\end{array}$ & $\begin{array}{c}\text { Duration } \\
(\mathrm{ms})\end{array}$ & $\begin{array}{l}\text { Amplitude } \\
(\mu \mathrm{V})\end{array}$ \\
\hline Supraorbital & $82 \pm 5$ & $1.62 \pm 0.223$ & $2.02 \pm 0.23$ & $0.9 \pm 0.28$ & $28 \pm 20$ \\
$\begin{array}{l}\text { Infraorbital } \\
\text { (paired difference with supraorbital) }\end{array}$ & $-2.6 \pm 3$ & $-0.18 \pm 0.28$ & $-0.20 \pm 0.21$ & $+0.1 \pm 0.3$ & $+5 \pm 20$ \\
& & $\mathrm{NS}$ & $\mathrm{NS}$ & $\mathrm{NS}$ & $\mathrm{NS}$ \\
$\begin{array}{l}\text { Mental } \\
\text { (paired difference with supraorbital) }\end{array}$ & $+39.8 \pm 9$ & $+0.72 \pm 0.38$ & $+0.88 \pm 0.36$ & $+0.3 \pm 0.25$ & $-15 \pm 14$ \\
& & $\mathrm{p}<0.01$ & $\mathrm{p}<0.01$ & $\mathrm{p} .<0.05$ & $\mathrm{p}<0.05$ \\
\hline
\end{tabular}

*Each subject was curarised, intraoperatively radiographed, and showed SAPs in all divisions.

also submitted to scalp recording (vertex-Cv7) of the early waves evoked by electrical stimulation of the infraorbital nerve. $^{10}$

Stimulation technique Details of surgical technique and of stimulation have been previously reported. ${ }^{3}$ A surgical cannula was inserted through the foramen ovale, under $x$ ray guidance with image intensification, and advanced until the tip reached the clival line on lateral $x$ ray projection. This position was considered to correspond to the trigeminal root at the level of the trigeminal incisura on the petrous bone. ${ }^{311-13}$ Different kinds of stimulating electrodes were used. Bipolar concentric stimulation was performed by means of an insulated stylet (cathode) with a $2 \mathrm{~mm}$ bare tip which protruded $1 \mathrm{~mm}$ from the teflon-coated surgical cannula, which had a $5 \mathrm{~mm}$ bare tip (anode). Unipolar stimulation was performed either by means of an insulated lead, with a $4 \mathrm{~mm}$ uninsulated cylindrical tip, or by the abovementioned stylet (either of the two being connected to the cathode, with the anode being placed on the ipsilateral earlobe). Square-wave negative pulses (0.05-0.1 ms duration, $0.5-15 \mathrm{~mA}$ intensity, $1-3 \mathrm{~Hz}$ frequency) were delivered.

Recording technique Antidromic sensory action potentials (SAPs) were recorded unipolarly from the supraorbital (V1-SAP), infraorbital (V2-SAP) and mental nerve (V3-SAP), by means of fine needle-electrodes (3 $\mathrm{mm}$ uninsulated tip) inserted into the homonymous foramina, the reference electrodes being placed subcutaneously $2-3 \mathrm{~cm}$ apart. Direct and reflex motor responses were recorded by surface electrodes placed over the masseter and orbicularis oculi muscles. Signals were amplified (band 5-5000 Hz), averaged (40-200 averages) and stored on floppy discs by means of a signal analyser (B.A.S.I.S. OTE). The onset latency of SAPs was measured at the first positive peak (P1), the peak latency at the negative peak $(\mathrm{N})$, the duration between the two positive peaks (P1-P2) and the maximum amplitude peak-topeak. Conduction velocity was computed taking both the onset latency (maximum CV) and the peak latency (peak CV) as conduction time.

In six selected cases (see below) the conduction distance between stimulating and recording electrodes was measured on radiographs in lateral projection (table 1 ). From measurements on 13 adult skulls, the average distance between the trigeminal incisura on the petrous bone and the three nerve outlets was $81 \mathrm{~mm}, 79 \mathrm{~mm}$ and $119 \mathrm{~mm}$, for the supraorbital, infraorbital and mental branches, respectively.

Statistical analysis was performed by Student's $t$ test for paired data (within-subject differences), analysis of variance (comparison among sub-groups of subjects) and $r$ coefficient of linear regression (correlation between age and $\mathrm{CV}$ ).

\section{Results}

Both the whole series of trigeminal reflexes ${ }^{9}$ and the early waves of trigeminal evoked potentials ${ }^{10}$ fell within normal limits in all subjects.

Intraoperative recordings from muscles showed that, in the awake subject, unipolar retrogasserian stimulation evoked direct motor responses at 2-2.5 ms latency from masticatory muscles (M-waves) and/or reflex responses at 8-13 ms latency from facia muscles (R1-like responses). ${ }^{4}$ With the bipolar con -9 centric stimulation, the appearance of $M$-waves or $\mathrm{R} 1$-like responses depended respectively on the exact positioning of the tip of the electrode within a lower or an upper division of the root. Signals from the supraorbital and infraorbital leads showed an early (1.9 ms peak latency), small and short-duration? potential which merged with or was followed by a series of slow and large deflections, ascribable to myogenic contamination from the surrounding masticatory and facial muscles. Signals from the mental lead were often completely obliterated by muscle artifacts (fig lbc).

In the anaesthetised and curarised subject, electric silence was obtained from muscle leads, while the slow deflections disappeared from the three cutaneous leads and an early and short potential $(2.7 \mathrm{~ms}$ peak latency) appeared in the signal from the mental nerve (fig ld). After the surgical lesion, electric silence was also obtained from the cutaneous leads in the divisions which were anaesthetic at postoperative clinical examination. It was concluded that the early and short-duration potentials recorded from the supraorbital, infraorbital and mental leads could be identified as compound sensory action potentials elicited antidromically by the retrogasserian stimuli.

In six selected cases, curarised and submitted to unipolar stimulation, SAPs were readily obtained from all three divisions (table 1). The potentials 
(a)

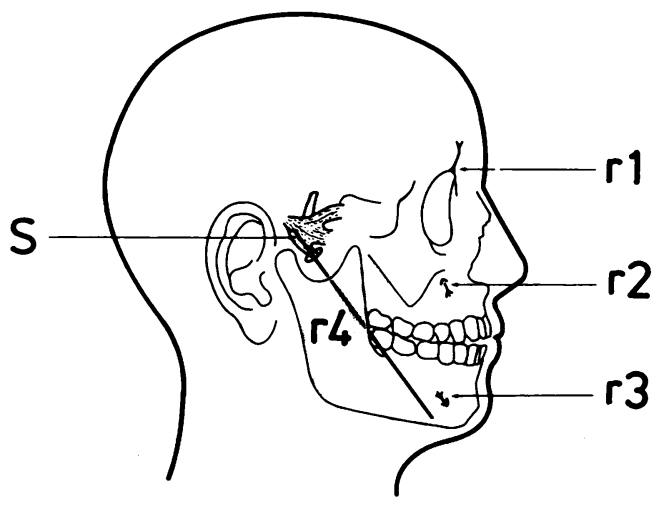

r 1

12

(b)

1

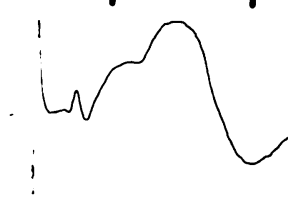

2

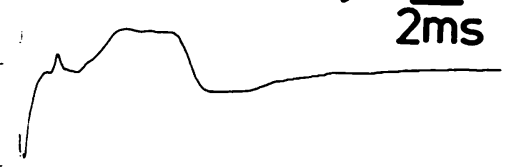

$r 3$

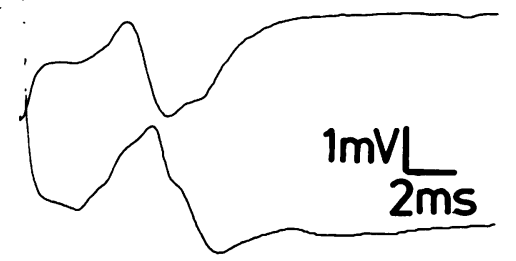

$r 4$

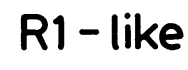

(c)

r 1

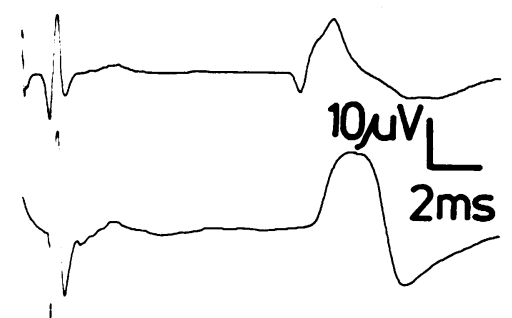

r3

I
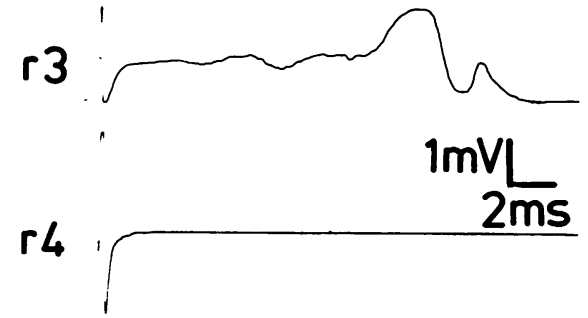

(d) SAP

r1
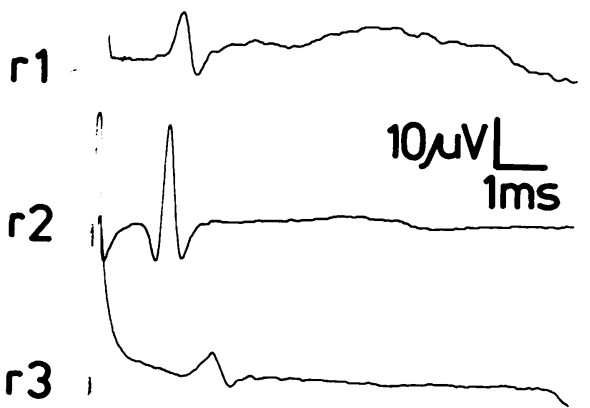

$1 \mathrm{mV}$

$1 \mathrm{~ms}$

Fig 1 Responses to retrogasserian stimulation in awake and in curarised subjects. (a) Schematic drawing showing stimulation and recording sites. Stimulation of retrogasserian root $(S)$. Recordings from the supraorbital $(r 1)$, infraorbital $(r 2)$ and mental $(r 3)$ nerves and from the masseter muscle $(r 4)$. (b,c) Responses in awake subjects to unipolar (b) and bipolar (c) stimulation. Note that small sensory potentials in $r 1$ and $r 2$ are followed by myogenic artifacts from masticatory $M$-waves (b) or facial Rl-like responses (c). (d) Responses in an anaesthetised and curarised subject to unipolar stimulation. Note sensory action potentials (SAPs) from the three cutaneous branches and electric silence from the muscle lead. 

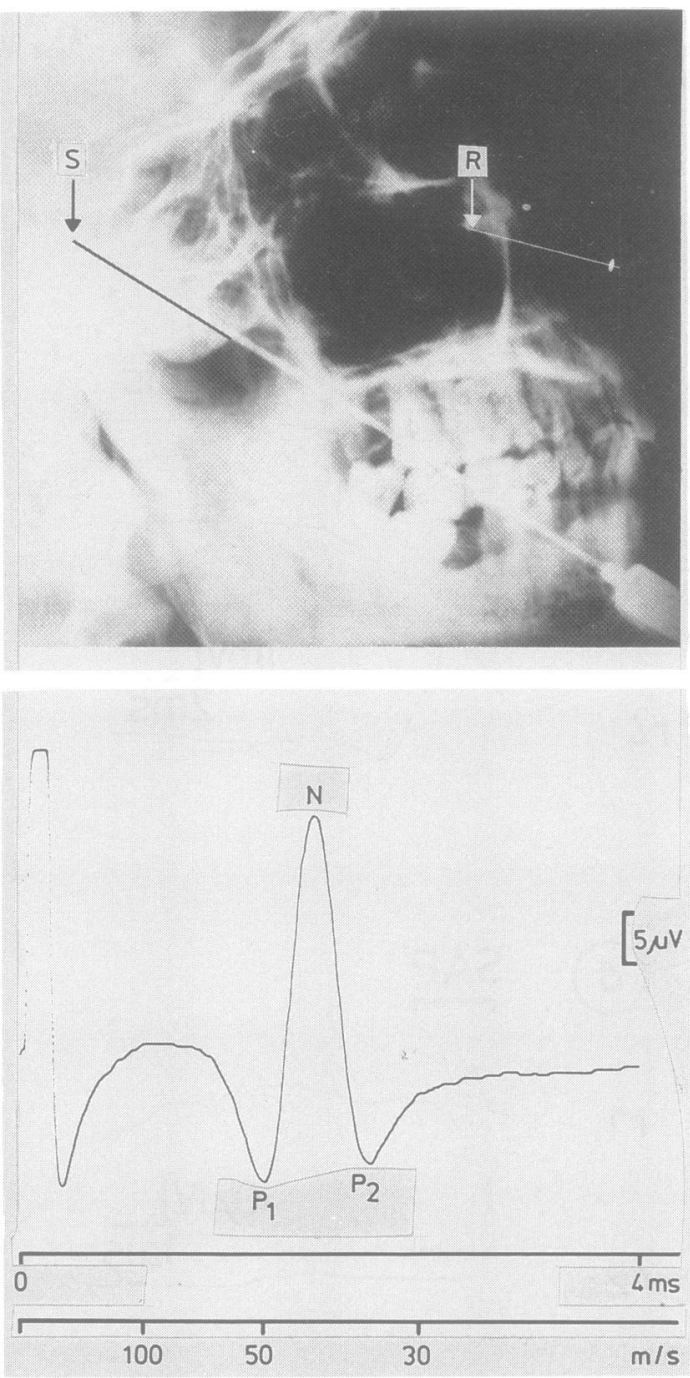

Fig 2 Measurement of sensory conduction velocity. Above: intraoperative radiograph showing stimulation at clivus level $(S)$ and recording at infraorbital canal $(R)$ (retouched). Conduction distance $80 \mathrm{~mm}$. Below: sensory action potential recorded from the infraorbital nerve. Maximum conduction velocity measured at the onset latency (PI) $51 \mathrm{~m} / \mathrm{s}$. Peak conduction velocity measured at peak latency $(N) 41 \mathrm{~m} / \mathrm{s}$.
Table 2 Frequency of SAPs obtained from the three trigeminal divisions in 18 subjects

\begin{tabular}{lllllllll}
\hline V1 & + & + & - & - & - & + & + & 11 \\
V2 & + & + & + & + & - & - & - & 15 \\
V3 & + & - & - & + & + & - & + & 10 \\
n & 6 & 4 & 3 & 2 & 2 & 1 & 0 & \\
\hline
\end{tabular}

Note that SAPs were most commonly obtained from V2, usually together with V1 and/or V3-SAPs. The absence of the V2-SAP never occurred with the concomitant presence of V1 and V3 SAPs.

showed a triphasic configuration (positive-negativepositive) and were similar in the supraorbital and infraorbital nerves, whereas the potential from the mental nerve had a slightly longer latency, longer duration and smaller amplitude. The differences between SAPs from V3 and from the other two divisions were statistically significant (table 1). Sensory conduction velocities were computed for each of the three branches, by measuring the conduction distances on intraoperative radiographs (fig 2). Maximum CV averaged $51-55 \mathrm{~m} / \mathrm{s}$ and peak CV 41-44 $\mathrm{m} / \mathrm{s}$, without significant differences between the three divisions.

There was no difference in SAP or CV data between the six selected subjects and the others, or between subjects affected by neuralgia and epilepsy. In addi tion, the measurement of conduction distances or radiographs (table 1) and on skulls (see Methods) yielded virtually equal values. We considered it therefore justified to average the data for the whole group of 18 subjects.

The occurrence of SAPs from each of the three divisions in the whole population is summarised in? table 2. A sensory potential was most frequently obtained from the infraorbital nerve ( $83 \%$ of cases), mainly in combination with SAPs from either of the two other divisions. Sensory CV was similar in the three divisions, though slightly lower for V1. The average values of maximum and peak $\mathrm{CV}$ were 52 and $39 \mathrm{~m} / \mathrm{s}$ for the first, 54 and $42 \mathrm{~m} / \mathrm{s}$ for the second and 54 and $44 \mathrm{~m} / \mathrm{s}$ for the third division (table 3). A significant inverse correlation $(p<0.05)$ was found between $\mathrm{CV}$ and age. Figure 3 shows the functions "age maximum-CV" and "age-peak CV" with values for the three divisions pooled. Maximum CV decreased from $59 \mathrm{~m} / \mathrm{s}$ (16 years) to $49 \mathrm{~m} / \mathrm{s}$ ( 73 years).

Table 3 Trigeminal SAPs and conduction velocity

\begin{tabular}{|c|c|c|c|c|c|c|}
\hline Nerve & $\begin{array}{l}\text { Onset latency } \\
(\mathrm{ms})\end{array}$ & $\begin{array}{l}\text { Conduction velocity } \\
(\mathrm{m} / \mathrm{s})\end{array}$ & $\begin{array}{l}\text { Peak latency } \\
\text { (ms) }\end{array}$ & $\begin{array}{l}\text { Conduction velocity } \\
(\mathrm{m} / \mathrm{s})\end{array}$ & $\begin{array}{l}\text { Duration } \\
\text { (ms) }\end{array}$ & $\begin{array}{l}\text { Amplitude } \\
(\mu V)\end{array}$ \\
\hline $\begin{array}{c}\text { Supraorbital } \\
(n=11) \\
\text { Infraorbital } \\
(n=15) \\
\text { Mental } \\
(n=10)\end{array}$ & $\begin{array}{r}1.58 \\
\pm 0.25 \\
1.47 \\
\pm 0.33 \\
2.23 \\
\pm 0.35\end{array}$ & $\begin{array}{c}51 \cdot 7 \\
+9 \\
53 \cdot 7 \\
\pm 9.4 \\
53.8 \\
\pm \quad 9\end{array}$ & $\begin{array}{c}2.06 \\
\pm 0.4 \\
1.9 \\
\pm 0.39 \\
2.71 \\
\pm 0.39\end{array}$ & $\begin{array}{r}39 \cdot 8 \\
\pm \quad 8 \cdot 8 \\
42 \cdot 3 \\
\pm 8 \cdot 4 \\
44 \\
\pm \quad 7 \cdot 1\end{array}$ & $\begin{array}{c}0.93 \\
\pm 0.4 \\
0.91 \\
\pm 0.3 \\
1.1 \\
\pm 0.2\end{array}$ & $\begin{aligned} & 27 \\
& \pm 28 \\
& 29 * \\
& \pm 20 \\
& 17 \cdot 5 \\
& \pm \\
& \pm 21\end{aligned}$ \\
\hline
\end{tabular}

*Average amplitude does not include responses from two cases (580 and $450 \mu \mathrm{V}$ ). 
(a)

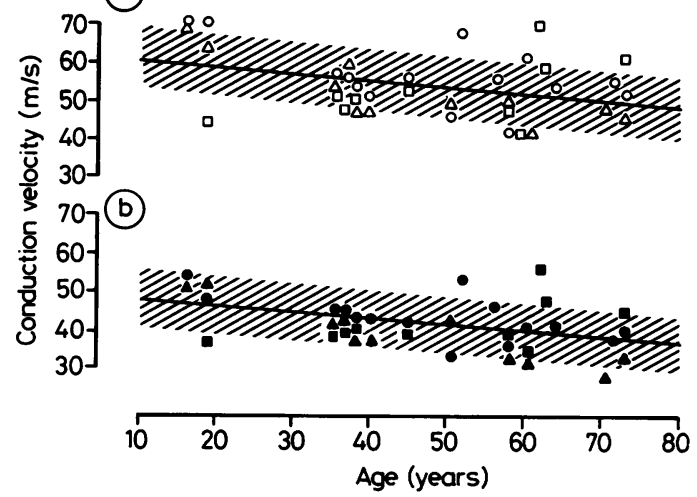

Fig 3 Age-dependence of sensory conduction velocity. Individual values of maximum $C V(a)$ and peak $C V$ (b) from the first (triangles), second (circles) and third (squares) division. Shaded areas are regression \pm standard error of the estimate.

Peak CV decreased from $47 \mathrm{~m} / \mathrm{s}$ (16 years) to $38 \mathrm{~m} / \mathrm{s}$ (73 years).

The infraorbital electrodes were left in situ when used as stimulating electrodes for recording of scalp potentials preoperatively and when used intraoperatively as recording electrodes. Assuming that ortho- and antidromic conduction velocities were equal, this allowed a direct comparison between evoked potentials and V2-SAP (fig 4). The second wave of the scalp potential, the so-called W2, was synchronous with or slightly later than the peak of the V2-SAP (1.9 ms), while the first wave (W1) had a latency of approximately half $(0.9 \mathrm{~ms})$.

\section{Discussion}

Electrophysiological findings in trigeminal neuralgia The question of electrophysiological abnormalities in trigeminal neuralgia is still a subject of controversy between authors who regard the finding of any abnormality as a sign of "symptomatic" neuralgia ${ }^{31415}$ and those who commonly find abnormalities in cases of otherwise "idiopathic" neuralgia. ${ }^{1617}$ The cause of disagreement may lie in the different methods of investigation, the first group of authors basing their opinion on testing of trigeminal reflexes and the second on cortical potentials evoked by stimulation in the trigeminal territory (TEPs). Both methods are open to criticism, since reflexes provide an indirect evaluation of trigeminal afferents through a motor response and the scalp potentials discussed here are bound to be contaminated by myogenic artifacts to such an extent that the cortical signal may be completely obscured. In this regard, it has recently been shown that curarisation conspicuously changes and
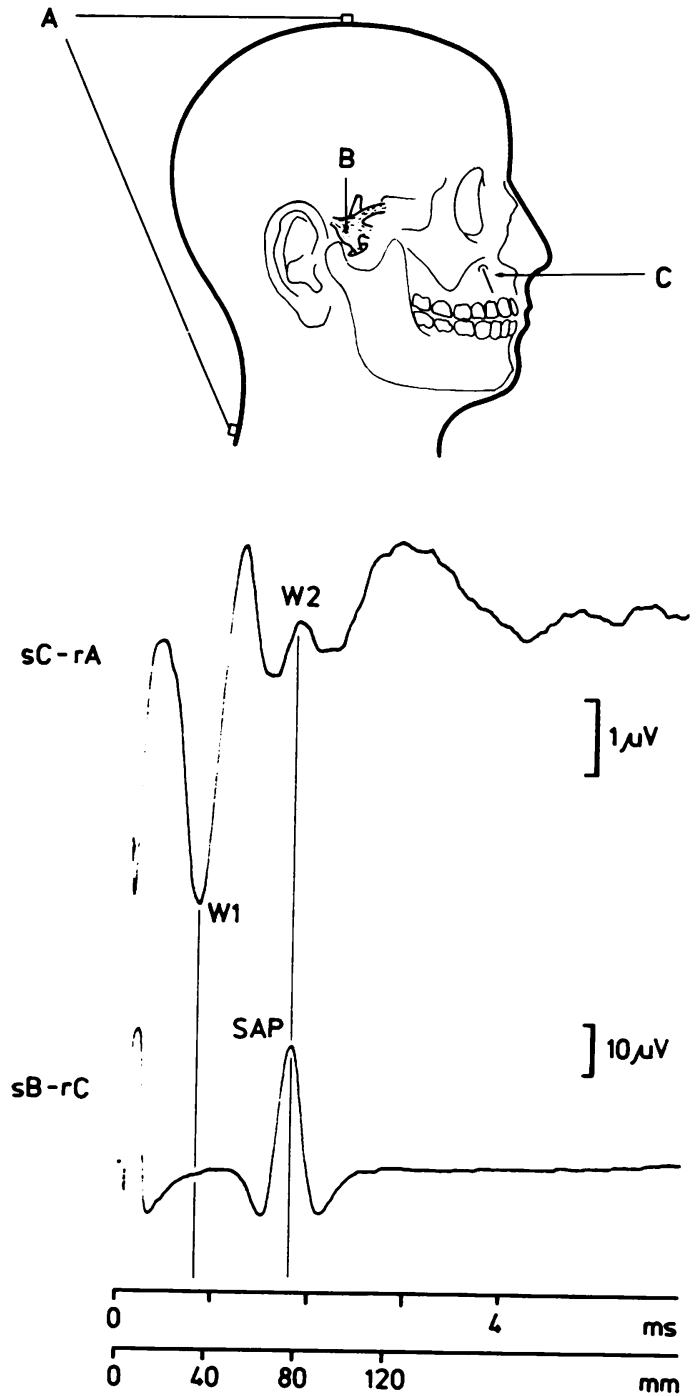

Fig 4 Comparison between scalp evoked potentials and antidromic action potentials. Above: schematic drawing showing stimulation and recording sites. $(A)$ scalp recording from Vertex $-C v 7$. (B) stimulation at clivus level. (C) infraorbital electrodes are used either for stimulation or recording. Below: scalp early waves (WI-W2) evoked by infraorbital stimulation $(s C-r A)$ and infraorbital action potential ( $S A P$ ) evoked by retrogasserian stimulation $(s B-r C)$. Note that peaks of W2 and SAP are synchronous.

flattens the signal beyond $10 \mathrm{~ms}$, and that only the early far-field potentials have an undoubtedly neural origin (nerve, root and brainstem). ${ }^{18}$

In our group of patients suffering from "idiopathic" trigeminal neuralgia, both the whole series of trigeminal reflexes ${ }^{9}$ and the early waves of TEPs ${ }^{10}$ 
(from the maxillary nerve and root) were normal. Furthermore, the sensory action potentials evoked by retrogasserian stimulation were identical to those of epileptic patients in whom there was no sign of trigeminal dysfunction. We conclude that, at least in the portion between the trigeminal incisura on the petrous bone and the nerve outlets on the face, sensory conduction in "idiopathic" neuralgia is normal. Naturally, with currently available electrophysiological methods it is impossible to detect dysfunctions involving only very few fibres or only small-diameter fibres, but both conditions might be sufficient to provoke paroxysmal pain.

Sensory action potentials and conduction velocity The sensory action potentials of the supraorbital, infraorbital and mental nerve were similar to those of limb nerves (fig 1d, table 3). A SAP was more commonly obtained from the infraorbital than from the other two branches (table 2). This could possibly be due to a series of concurring factors. Lying in an intermediate position within the root, the fibres of the second division are more likely to be reached by the stimulus. Because the recording electrode is inserted into the infraorbital canal, which can be easily identified and penetrated, it lies very close to the nerve. In two cases the amplitude of the V2-SAP even reached $580 \mu \mathrm{V}$ and $450 \mu \mathrm{V}$, possibly because the tip of the recording electrode had pierced the nerve sheaths, and penetrated among the nerve fibres. The SAP from the mental nerve had a longer latency than that from the other two branches (table 3). This was attributed to the longer conduction distance; the conduction velocity was indeed similar in the three divisions, though slightly lower in the first division.

Maximum CV was, on average, $52 \mathrm{~m} / \mathrm{s}$ for $\mathrm{V} 1$ and $54 \mathrm{~m} / \mathrm{s}$ for V2 and V3 (table 3); it was inversely correlated with age, slowing from $59 \mathrm{~m} / \mathrm{s}$ (16 years) to 49 $\mathrm{m} / \mathrm{s}$ (73 years) (fig 3). The accuracy of these measurements was necessarily limited, both because the conduction distance was somewhat short $(8-12 \mathrm{~cm})$ and the conduction time was computed between stimulating and recording electrodes instead of between two sets of recording electrodes. However, the same method is commonly used for sensory CV measurement in the finger-wrist portion, with distances of $12-17 \mathrm{~cm} .{ }^{19}$

Maximum CV of trigeminal sensory fibres (49-59 $\mathrm{m} / \mathrm{s})$ was lower than that of trigeminal motor fibres $(55-68 \mathrm{~m} / \mathrm{s}),{ }^{3}$ at variance with findings in the mixed nerves of limbs. This can be ascribed to the absence of large-sized proprioceptive A alpha fibres in the cutaneous branches of the trigeminal nerve. Accordingly, the largest fibres of the human trigeminal motor root have diameters of $14 \mu \mathrm{m}$ and over, ${ }^{20}$ while those of the sensory root reach only $11 \mu \mathrm{m} .{ }^{21}$ Similarly, the masticatory nerves in animals contain fibres larger by
$3 \mu \mathrm{m}$ than the frontal, infraorbital and inferior dental nerves. ${ }^{22}$ In two post-mortem specimens we found the largest fibres to be 10-11 $\mu \mathrm{m}$ in the ophthalmic, 11-12 $\mu \mathrm{m}$ in the maxillary and $14-16 \mu \mathrm{m}$ in the mandibular nerve (containing motor fibres) (unpublished data). Other purely cutaneous nerves, such as the sural, saphenous and superficial radial, show a conduction velocity somewhat higher than the trigeminal sensory $\mathrm{CV}$, but also have slightly larger nerve fibres. A survey of reports on the human sural nerve, the most widely studied cutaneous nerve, shows that maximum conduction velocities range between 50 and $62 \mathrm{~m} / \mathrm{s}$, while the largest diameters are between 12 and $14.5 \mu \mathrm{m} .{ }^{23-28}$ Age-dependence is also a common feature of conduction velocity in human nerves. According to the age-CV function computed by Buchthal, ${ }^{23}$ maximum $\mathrm{CV}$ in the sural nerve would be $57 \mathrm{~m} / \mathrm{s}$ at 16 and decrease to $54 \mathrm{~m} / \mathrm{s}$ at 73 years.

The "peak" conduction velocity of trigeminal sensory fibres was on average $39 \mathrm{~m} / \mathrm{s}$ for V1, $42 \mathrm{~m} / \mathrm{s}$ for $\mathrm{V} 2$ and $44 \mathrm{~m} / \mathrm{s}$ for V3. An age-related decline was evident, the average velocity of the three branches falling from $47 \mathrm{~m} / \mathrm{s}$ to $38 \mathrm{~m} / \mathrm{s}$. Conventional clinical measurement of conduction velocity has focussed primarily on the fastest-conducting fibres. Peak CV (that is the velocity computed taking the negative peako latency as conduction time) is commonly used only when there is some difficulty in evaluating the onseti latency. However, since the time of Gasser, studies of the reconstruction of the compound action potential based on electrophysiological and histometric data have shown that the nerve potential is determined by the relative density of functioning fibres in the various regions of the velocity spectrum. ${ }^{29-32}$ In unipolar recordings the peak of the potential would correspond, though approximately, to the conduction time of the main bulk of fibres the diameter of which is coincident with the peak of the larger fibres in the histogram. ${ }^{192729}$ We believe that the peak latency and velocity are useful in comparing results with latencies and estimates of conduction velocity derived from studies on trigeminal evoked potentials or trigeminal reflexes. Considering how small a proportion of the total nerve-fibre population the fastestconducting fibres represent, they are unlikely to be responsible for either evoked potentials or reflexes.

Comparison with previous electrophysiological findings on trigeminal nerve conduction Ley et al ${ }^{1}$ took recordings from the trigeminal root during surgery by the transcerebellar route. They stimulated the cutaneous branches and recorded unipolarly from the root close to the pons entry. Stimulation of the supraorbital nerve yielded satisfactory recordings in a sufficient number of cases. The onset latency for the V1-elicited potential was $1.9 \mathrm{~ms}$. A conduction velocity of about $50 \mathrm{~m} / \mathrm{s}$ was proposed. In the present 
study, the onset latency of the V1-SAP was $1.6 \mathrm{~ms}$. Since our retrogesserian stimulation site was at the level of the trigeminal incisura, the conduction distance was about 15-17 mm shorter than that of Ley and coworkers. ${ }^{1112} \mathrm{~A}$ maximum $\mathrm{CV}$ of $50-55 \mathrm{~m} / \mathrm{s}$ along the root would account for the latency difference.

Drechsler $^{33}$ has suggested a conduction time of $5 \mathrm{~ms}$ for the nerve portion between the ganglion and the peripheral outlets of the cutaneous branches. This author attempted intraoperative recording of both antidromic and orthodromic sensory signals. Recordings from the cutaneous branches were completely obscured by slow artifacts starting at $2 \mathrm{~ms}$, with a $5 \mathrm{~ms}$ peak, and lasting several milliseconds (possibly far-field potentials from $\mathrm{M}$-waves of masticatory muscles). Orthodromic recordings from the ganglion showed a slow deflection as well, but this was preceded by a small short-duration wave, $2 \mathrm{~ms}$ peak latency, not described by the author, which had the features of a neural signal and fits with our own SAPs, peaking at about $2 \mathrm{~ms}$.

Leandri and coworkers ${ }^{210}$ have described the early waves of the scalp potentials following stimulation of the infraorbital nerve. The first three waves, named W1-W2-W3, were supposed to originate respectively from the point of entry of the maxillary nerve into the ganglion, the point of entry of the root into the pons, and the presynaptic portion of the spinal tract. A conduction velocity of $40 \mathrm{~m} / \mathrm{s}$ was proposed for $\mathrm{V} 2$ fibres. This estimate is far lower than our values for maximum CV, but it was derived from peak latencies and should therefore be compared with our peak $\mathrm{CV}$, that is, $42 \mathrm{~m} / \mathrm{s}$ for V2-fibres. According to recordings of scalp potentials and SAPs in our group, the generators of these early waves are slightly more distal than those indicated by Leandri and coworkers. In our subjects the scalp wave W2 coincided with the peak of the V2-SAP (fig 4), thus its generator should correspond to the root at the level of the trigeminal incisura on the petrous bone, while W1, its latency being half that of the SAP, probably originates halfway between the trigeminal incisura and the infraorbital foramen, that is at the level of inferior fissura on the orbital floor.

The estimates of trigeminal sensory $\mathrm{CV}$ derived from blink reflex studies are necessarily indirect, being based on reflex latencies, in which the synaptic delay could not be precisely accounted for. A first group of authors, supporting the view that the early component of the blink reflex is myotatic, proposed values of approximately $70 \mathrm{~m} / \mathrm{s}$, that is, in the range of A alpha proprioceptive fibres. ${ }^{34-36}$ This estimate exceeds the maximum $\mathrm{CV}$ we were able to compute by direct measurement, and can no longer be maintained. A second group of authors, supporting the view that the reflex is cutaneous, reported values of 33- $44 \mathrm{~m} / \mathrm{s}$ for $\mathrm{V} 1^{37}$ and $39-44 \mathrm{~m} / \mathrm{s}$ for $\mathrm{V} 2,{ }^{4}$ falling in the range of intermediately-fast conducting fibres. These values are consistent with the average peak $\mathrm{CV}$ reported here $(39 \mathrm{~m} / \mathrm{s}$ for $\mathrm{V} 1$ and $42 \mathrm{~m} / \mathrm{s}$ for V2).

Surgical significance Besides providing data on trigeminal nerve physiology, the technique of retrogasserian stimulation, as described in this paper and two earlier publications, ${ }^{34}$ might be helpful in operations for the treatment of trigeminal neuralgia. At present, the subject's collaboration is necessary both to identify the proper division within the root and to assess the effect of the surgical lesion, which slows the operation and is uncomfortable for the patient. We have observed that bipolar concentric stimulation selectively evokes direct motor responses or sensory potentials from upper or lower divisions depending on the positioning of the intracranial needle, and that the surgical manoeuvre can suppress the potentials. Once the method is standardised, it should be possible to perform the operation under continuous general anaesthesia.

We thank Dr D Bowsher for his advice and Drs $\mathbf{R}$ Cattin and V D'Annunzio for their collaboration during the recordings.

This work was supported by Ministero Pubblica Istruzione of Italy, Rome.

\section{References}

1 Ley A, Montserrat L, Bacci F, Ley A. Clinical and electrophysiological studies on sensory conduction mediated by the accessory rootlets of the human trigeminal nerve. J Neurosurg 1975;42:413-21.

2 Leandri M, Campbell JA. Origin of early waves evoked by infraorbital nerve stimulation in man. Electroencephalogr Clin Neurophysiol 1986;65:13-9.

3 Cruccu G. Intracranial stimulation of the trigeminal nerve in man. I. Direct motor responses. J Neurol Neurosurg Psychiatry 1986;49:411-8.

4 Cruccu G, Bowsher D. Intracranial stimulation of the trigeminal nerve in man. II. Reflex responses. $J$ Neurol Neurosurg Psychiatry 1986;49:419-27.

5 Wieser HG, Elger CE, Stodieck SRG. The "Foramen ovale electrode": a new recording method for the preoperative evaluation of patients suffering from mesiobasal temporal lobe epilepsy. Electroencephalogr Clin Neurophysiol 1985;61:314-22.

6 Sweet WH, Wepsic JG. Controlled thermocoagulation of trigeminal ganglion and rootlets for differential destruction of pain fibres. Part 1. Trigeminal neuralgia. J Neurosurg 1974;40:143-56.

7 Mullan S, Lichtor T. Percutaneous microcompression of the trigeminal ganglion for trigeminal neuralgia. $J$ Neurosurg 1983;59:1007-12.

8 Meglio M. Percutaneously implantable chronic electrode for radiofrequency stimulation of the gasserian ganglion. Acta Neurochir (Wien) 1984;suppl 33:521-5. 
9 Cruccu G, Inghilleri M, Fraioli B, Guidetti B, Manfredi M. Neurophysiological assessment of trigeminal function after surgery for trigeminal neuralgia. Neurology 1987;37:631-8.

10 Leandri M, Parodi CI, Favale E. Early evoked potentials detected from the scalp of man following infraorbital nerve stimulation. Electroencephalogr Clin Neurophysiol 1985;62:99-107.

11 Gudmundsson K, Rhoton AL, Rushton JG. Detailed anatomy of the intracranial portion of the trigeminal nerve. $J$ Neurosurg 1971;35:592-60.

12 Lang J. Clinical Anatomy of the Head. Heidelberg: Springer, 1983.

13 Tew JM. Treatment of trigeminal neuralgia by percutaneous rhizotomy. In: Youmans JR, ed. Neurological Surgery. vol. 6. Philadelphia: WB Saunders Co., 1982.

14 Kimura J, Rodnitzky RL, Van Allen WM. Electrodiagnostic study of the trigeminal nerve. Orbicularis oculi reflex and masseter reflex in trigeminal neuralgia, paratrigeminal syndrome and other lesions of the trigeminal nerve. Neurology 1970;20:574-83.

15 Ongerboer de Visser BW, Goor C. Electromyographic and reflex study in idiopathic and symptomatic trigeminal neuralgias: latency of the jaw and blink reflexes. J Neurol Neurosurg Psychiatry 1974;37: 1225-30.

16 Stohr M, Petruch F. Somatosensory evoked potentials following stimulation of the trigeminal nerve in man. J Neurol 1979;220:95-8.

17 Bennett MH, Jannetta PJ. Evoked potentials in trigeminal neuralgia. Neurosurgery 1983;13:242-7.

18 Leandri M, Parodi C, Zattoni J, Favale E. Post-synaptic components of the trigeminal evoked potentials in man. Electroencephalogr Clin Neurophysiol 1987; 66:253-62.

19 Buchthal F, Rosenfalck A. Evoked action potentials and conduction velocity in human sensory nerves. Brain Res 1966;3:1-122.

20 Young RF, Stevens R. Unmyelinated axons in the trigeminal motor root of humans and cat. J Comp Neurol 1979;183:205-14.

21 Young RF. Fibre spectrum of trigeminal sensory root of cat, frog and man determined by electronmicroscopy. In: Anderson DJ, Matthews B, eds. Pain in the Trigeminal Region. Amsterdam: Elsevier 1977:137-47.

22 Windle WF. The distribution and probable significance of unmyelinated nerve fibers in the trigeminal nerve of the cat. J Comp Neurol 1926;41:453-77.

23 Buchthal F. Electromyography (Part A). In: Remond A, ed. Handbook of Electroencephalography and Clinical Neurophysiology. vol. 16. Amsterdam: Elsevier 1975.

24 Tackmann W, Spalke G, Oginszus HJ. Quantitative histometric studies and relation of number and diameter of myelinated fibres to electrophysiological parameters in normal sensory nerves of man. $J$ Neurol 1976;212:71-84.

25 Behse F, Buchthal F. Sensory action potentials and biopsy of sural nerve in neuropathy. Brain 1978; 101:473-93.

26 Caruso G, Santoro L, Perretti A, et al. Friedreich's ataxia: electrophysiological and histological findings. Acta Neurol Scand 1983;67:26-40.

27 Dyck PJ, Thomas PK, Lambert EH, Bunge R, eds. Peripheral Neuropathy. Philadelphia: WB Saunders Co., 1984.

28 Stegeman DF, De Weerd JPC. Modelling compound action potentials of peripheral nerves in situ. I. Model description; evidence for a non-linear relation between fibre diameter and velocity. Electroencephalogr Clin Neurophysiol 1982;54:436-48.

29 Gasser HS, Erlanger J. The role played by the sizes of the constituent fibers of a nerve trunk in determining the form of its action potential wave. Am $J$ Physiol 1927;80:522-47.

30 Gasser HS, Grundfest H. Axon diameters in relation to the spike dimensions and the conduction velocity in mammalian A fibers. Am J Physiol 1939;127:393-414.

31 Dorfman LJ, Cummins KL, Leifer LJ, eds. Conduction Velocity Distribution: A Population Approach to Elec trophysiology of Nerve. New York: Alan R Liss, 1981 ก

32 Dorfman LJ. The distribution of conduction velocitie (DCV) in peripheral nerves: a review. Muscle \& Nerve 1984;7:2-11.

33 Drechsler F. Short and long latency cortical potentials following trigeminal nerve stimulation in man. Ins Barber C, ed. Evoked Potentials. Baltimore: Universite Press. 1980:415-22.

34 Kugelberg E. Facial reflexes. Brain 1952;75:385-96.

35 Struppler A, Dobbelstein H. Elektromyographische Untersuchung des Glabellareflexes bei verschiedenen neurologischen Stoerungen. Nervenartz 1963;34: 347-52.

36 Trontelj MA, Trontelj JV. Reflex arc of the first component of the human blink reflex: a single motoneurone study. $J$ Neurol Neurosurg Psychiatry 1978;41:538-47.

37 Shahani BT. The human blink reflex. J Neurol Neurosurg Psychiatry 1970;33:792-800. 